\section{A última morte de Lourival: a cisgeneridade como metanarrativa sobre os corpos no jornalismo}

\author{
Alisson Machado \\ Marlon Santa Maria Dias
}

\section{Resumo:}

O objetivo do artigo é discutir as formas como a cisgeneridade opera nas racionalidades que orientam as práticas jornalísticas. Essa reflexão é realizada a partir da análise de um caso exemplar: descrevem-se as estratégias narrativas de objetivação e subjetivação encontradas na reportagem televisiva $O$ segredo de Lourival, veiculada em 2019 pelo Fantástico (Rede Globo). Na reportagem, Lourival Bezerra de Sá é apresentado não como uma pessoa transgênera, mas como "uma mulher que se passou por homem durante décadas". As estratégias apontam para a cisgeneridade como uma metanarrativa, plano de fundo que sustenta o entendimento dos corpos pelo jornalismo, dimensão de caráter fabular e moralista que oblitera a interpretação da complexidade da vida social atuando na manutenção da precariedade dos regimes simbólicos ao ponto de criminalizar as identidades gênero-divergentes.

Palavras-chave: Reportagem. Estratégias narrativas. Cisgeneridade.

Lourival's last death: cisgenerity as a metanarrative about bodies in journalism

\begin{abstract}
:
The aim of the article is to discuss the ways cisgenerity operates in the rationalities that guide journalistic practices. This reflection is based on the analysis of an exemplary case: we describe the narrative strategies of objectification and subjectification found in the television feature Lourival's secret, broadcasted in 2019 by Fantástico (a variety news program from Brazil's biggest broadcaster Rede Globo). The feature presented Lourival Bezerra de Sá not as a transgender person, but as "a woman who impersonated a man for decades". The strategies point to cisgenerity as a metanarrative, a background that supports the understanding of bodies by journalism, a fable and moralistic vision of character that obliterates the interpretation of the social life complexity, acting in the maintenance of the precariousness of symbolic regimes to the point of criminalizing gender-divergent identities.
\end{abstract}

Keywords: Journalism. Narrative strategies. Cisgenerity.
Recebido em: 20.03.20

Aprovado em: 21.02.21

Alisson Machado

Doutor em Comunicação pela Universidade Federal de Santa Maria. Mestre e Bacharel em Comunicação Social, habilitação em Jornalismo, pela mesma instituição. Professor temporário na Universidade Federal de Santa Catarina.

E-mail: machado.alim@ gmail.com

\section{Marlon}

\section{Santa Maria Dias}

Doutorando em Ciências da Comunicação na Unisinos, com bolsa CAPES/Proex. Mestre em Comunicação e Bacharel em Comunicação Social, habilitação em Jornalismo, pela Universidade Federal de Santa Maria.

E-mail:marlon.smdias@ gmail.com

Estudos em Jornalismo e Mídia v.18, n.1, jan./jun. 2021. ISSNe 1984-6924 
${ }^{1}$ Uma versão prévia deste texto foi apresentada no $17^{\circ}$ Encontro Nacional de Pesquisadores de Jornalismo em 2019.

${ }^{2} \mathrm{O}$ termo cisgênero é utilizado para indicar pessoas cuja identidade de gênero concorda com o gênero que lhes foi atribuído. Portanto, estaria em oposição (e como norma referencial) à indicação transgênero - pessoa cuja identidade de gênero diverge daquela que lhe foi designada. No artigo, entendemos a noção de cisgênero como referência a uma condição sociopolítica e sociocorporificada que demarca privilégios - ou seja, sujeitos cuja identidade de gênero é respeitada e legitimada (LANZ, 2017).

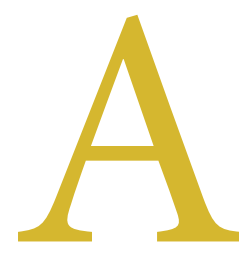

o construir narrativas, o jornalismo produz saberes acerca dos acontecimentos e contribui para a compreensão das alteridades (RESENDE, 2009), constituindo importante instância de elaboração das inteligibilidades possíveis à construção social. Os textos jornalísticos ofertam uma interpretação da realidade, "apresentada a partir de visões de mundo predominantes que trazem implícitas nossos sistemas e hierarquias de valores hegemônicos - como os de gênero, de classe, de raça - e que parecem não ser refletidas criticamente no fazer jornalístico" (VEIGA DA SILVA, 2015, p. 22). ${ }^{1}$

Ao considerarmos o jornalismo uma prática que se efetiva sobre valores e posições hegemônicas (VEIGA DA SILVA, 2015), entendemos que sua racionalidade se constitui no masculino, em um paradigma moderno-positivista e em relação a um sistema-mundo (GROSFOGUEL, 2012) capitalista, masculinista, racista, heterossexista, ocidentalista e, acrescentamos, cisgênero ${ }^{2}$. Essa racionalidade orienta, muitas vezes, práticas jornalísticas pouco afeitas à alteridade, com lentes de inteligibilidade que excluem, exotizam ou criminalizam sujeitos que não se enquadram nas normas sociais.

A observação de acontecimentos contemporâneos que se constituem nos tensionamentos sobre gênero tem se mostrado uma importante operação para a pesquisa em jornalismo - tanto para entender a circulação desses discursos quanto para a compreensão da prática jornalística em si (HUERTA, 2009). Por envolver valores e crenças naturalizados, as discussões relacionadas a gênero se inserem no campo dos dissensos sociais. Cada vez mais tensionado pela circulação de discursos advindos de diferentes campos sociais, o jornalismo disputa com outros atores o estatuto narrativo de referência. A compreensão dos componentes que conformam a tematização desses acontecimentos dá acesso a uma complexa trama simbólica na qual o jornalismo ainda é um importante artífice.

O objetivo deste artigo é discutir a cisgeneridade como uma racionalidade que orienta o jornalismo, uma ação cognitivo-narrativa sobre o tema da inteligibilidade dos corpos pela fixação do binômino sexo-gênero como masculino ou feminino. Essa ação parte da naturalização da cisgeneridade dos corpos e, a partir disso, da produção sistêmica da transgeneridade no campo da anormalidade, da falsidade, da iniquidade ou das patologias. Para tanto, analisamos um caso exemplar: uma reportagem veiculada pelo programa televisivo Fantástico, da Rede Globo, sobre a morte de Lourival Bezerra de Sá, que é apresentado como "uma mulher que se passou por homem", "segredo" descoberto após a sua morte. Quatro meses depois, época em que a reportagem foi veiculada, seu corpo ainda estava no Instituto de Medicina Legal, impedido de ser enterrado pela "divergência de gênero".

A análise não intui generalizar ou reduzir a compreensão das práticas jornalísticas sobre o tema a uma reportagem em si. No entanto, entende essa narrativa como sintoma de uma racionalidade social ampla e reconhecida que se elabora nos jogos de força entre os contornos da narração midiática e aquilo que extrapola as suas fronteiras. Em sua dimensão narrativa, a reportagem carrega marcas do processo social de produção do sentido que podem ser examinadas. Mediadora das práticas sociais em conceitos simbólicos tangíveis porque representáveis (HALL, 2016), a narrativa jornalística não é autônoma aos demais discursos que circulam em uma sociedade. Ela não está deslocada dos sistemas de apreensão das realidades, pois, nas formas em que se realiza e naquilo que produz, mobiliza sentidos em curso, estando eles em permanente reelaboração ou já cristalizados no tecido social. As narrativas jornalísticas demarcam, embora não sem disputa, modos específicos de dizer sobre o que narram, "inscrevendo e excluindo sujeitos, ressaltando e apagando saberes e poderes, concedendo e negando espaços e direitos" (RESENDE, 2011, p. 134). 
$\mathrm{O}$ artigo se estrutura em três partes. Na primeira, apresenta uma descrição da reportagem identificando estratégias de objetivação e subjetivação da narrativa jornalística. As estratégias de objetivação são responsáveis pelo efeito do real, recursos que intentam interpelar a audiência em torno das condições de verdade que os fatos narrados portam (MOTTA, 2008). As estratégias de subjetivação indicam os efeitos poéticos, retóricos e figurativos da narrativa pelos quais, ao conectar partes, a história é ressubjetivada (MOTTA, 2008). Na segunda, a partir da descrição, aponta-se um tipo específico de racionalidade em funcionamento através dessas estratégias. A terceira interpreta a cisgeneridade como uma metanarrativa ${ }^{3}$ que interpela a inteligibilidade dos corpos transgêneros e atua na manutenção da precariedade dos regimes simbólicos.

\section{Da reportagem}

Construir enunciados que despertam curiosidade é prática recorrente para a manutenção da audiência em diferentes formatos televisivos. As chamadas dos programas telejornalísticos operam nessa lógica, com o resumo das principais matérias de cada edição. Observando as chamadas da edição de 3 de fevereiro de 2019 do Fantástico, nota-se o destaque a uma reportagem: em tom dramático, o texto anunciava que o programa apresentaria o "mistério" que ronda a história de um homem que "escondeu" por décadas um "grande segredo". E pergunta: "afinal, qual o segredo de Lourival?"

Os apresentadores introduzem a matéria, de 7 minutos e 50 segundos, dizendo que Lourival escondeu um segredo da própria família com quem viveu por mais de 40 anos, e que, depois do "choque da descoberta", seu corpo não poderia ser enterrado. A reportagem inicia com uma estratégia de objetivação (por testemunho) com o depoimento de três pessoas sem identificação nominal - depois informa que são vizinhos e amigos de Lourival. Elas afirmam que ele era "uma pessoa boa", que "fazia muita caridade" e que costumava ajudar todo mundo. A repórter narra em off, evidenciando outras estratégias de objetivação (por indexação temporal e circunstancial): " 5 de outubro de 2018. Lourival Bezerra de Sá, 78 anos, passa mal e tem um enfarto fulminante em casa. O corpo vai para o Serviço de Verificação de Óbito. E, então, a surpresa”. Na sequência, duas fontes peritas são mobilizadas: o agente de polícia diz: "O corpo chegou lá com divergência de gênero"; o médico legista corrobora: "Uma pessoa era identificada como sexo masculino, mas no atendimento médico já foi constatado que era uma pessoa do sexo feminino. Nunca tive nenhum caso parecido". A voz em off segue: "Há quase quatro meses, o mistério impede o enterro do corpo de Lourival".

A narração é ilustrada com a imagem gráfica de um quadro de cortiça, com fotografias de Lourival e post-its afixados (Figura 1) - remetendo aos quadros utilizados nas investigações policiais, com informações sobre suspeitos, testemunhas e pistas para se solucionar um caso. Esse recurso é a principal estratégia de subjetivação da narrativa: a de que existe um mistério, um segredo, algum sujeito que logrou enganar e que o trabalho jornalístico desvendou a história. Logo após a última narração citada, lê-se em um dos post-its: "O SEGREDO DE LOURIVAL".

Figura 1 - Estratégias narrativas

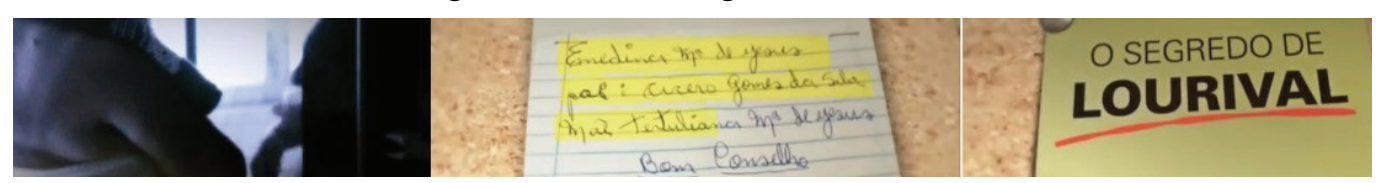

Fonte: Rede Globo, 2019 (captura de tela realizada pelos autores).
${ }^{3}$ A metanarrativa diz respeito aos significados de fundo moral, ação prescritiva, normativa, pedagógica e de ordem fabular de uma história. Possui uma função cosmológica de contenção das transgressões (éticas) contra um regime simbólico estabelecido (MOTTA, 2008). 
$\mathrm{Na}$ abertura, o único termo que faz referência à identificação de Lourival como uma pessoa transexual pode ser deduzido da fala do agente de polícia. Ao indicar que nunca tinha visto nada parecido, o médico qualifica a situação como incomum, desconsidera a existência sociocorporificada das pessoas transexuais e lança o problema biopolítico instaurado pelo não reconhecimento do gênero de Lourival para o campo do improvável, do absurdo, situação que nem mesmo seu capital simbólico, prestígio e autoridade médica conseguem explicar.

Em seguida, o texto jornalístico utiliza dois termos que passam a ser recorrentes: mistério e segredo. A construção audiovisual da reportagem também busca imprimir o sentido dessas expressões na narrativa: investigação aos moldes do imaginário criminal, identificação do suspeito, estética noir, imagem granulada e em escala de cinza, uso de simulação, trilha sonora carregada de tensão cujas notas musicais agudas reintroduzem na narrativa uma atmosfera de incógnita e charada são estratégias que conformam uma intriga dramática (MOTTA, 2013).

A narração segue mobilizando estratégias de objetivação, apontando acontecimentos cronológicos e fontes envolvidas: "Para entender essa história, é preciso voltar 50 anos no tempo. Primeira parada: Goiânia. É aqui que Lourival conhece Maria Olina. Juntos registram 4 filhos". Glaydiany, uma das filhas de Lourival e única parente entrevistada, diz: "Lembrança dele, afetiva, não... Tenho poucas, porque eu tinha cinco anos quando minha mãe faleceu. [...] Lembro dos meus irmãos falar que minha mãe morou com ele um tempo, que tinha um bar com ele lá em Ituverava [São Paulo]". A relação entre pai e filha não é explorada, ainda que o trecho sugira que eles não mantinham relação de convivência.

A repórter explica que Lourival e Maria Olina se mudaram de Goiás para São Paulo e, após a separação, ele foi sozinho para Cuiabá (MT). O texto off é coberto pela imagem gráfica do quadro de cortiça, no qual aparecem fotografias afixadas (das personagens da reportagem) e o mapa do Brasil - a imagem será recorrente para cobrir as falas da repórter e sinalizar as cidades nomeadas - como se a reportagem percorresse as trilhas de Lourival.

A delegada explica que, em Cuiabá, Lourival conheceu sua "cuidadora" e de lá foi para Campo Grande (MS), cidade onde residiu até morrer. A cuidadora "que o acompanhou por quase 40 anos" não tem o nome revelado e a repórter informa que ela não quis dar entrevista. O texto cita que Lourival assumiu a filha dela e juntos adotaram outro menino. Na entrevista, a delegada afirma que os dois não tinham uma relação marital: "O que se percebe é que existiu um companheirismo entre a Lourival e a cuidadora, mas não existiu de fato uma relação como se fosse marido e mulher. Então, era como se fosse um acordo de convivência entre ambos e juntos criariam os filhos". Ao flexionar o artigo no feminino e frisar o "a", a delegada atribui o gênero feminino a Lourival a partir de uma concepção biológica dos corpos, cuja abordagem identifica mulher transexual como macho e homem transexual como fêmea (JESUS, 2013). Ademais, ela expressa uma compreensão da relação afetivo-conjugal orientada pela necessidade do intercurso sexual, que desconsidera o arranjo familiar estabelecido, colocando sob suspeita a natureza da relação entre eles.

A repórter questiona: "Mas como Lourival, que na verdade era mulher, pôde se passar por homem durante tanto tempo? Para a polícia, a cuidadora disse que tinha desconfianças". É significativo que tanto a delegada quanto a repórter insistam em uma ontologia do sujeito exterior à própria vontade. A falsidade ideológica com que compreendem Lourival parece ser o único enquadramento possível para a sua existência, alguém que mentiu e se escondeu durante toda a vida, orientação tomada a partir da relevância do dado biológico.

O depoimento de uma vizinha aparece para explicar as desconfianças. Ela conta que a cuidadora confidenciou que Lourival não deixava que dessem banho nele. "Até que um dia ela deu banho nele. Foi aí então que ela achou a faixa. Diz 
que... uma faixa amarrada nos seios". A fala do médico confirma o comentário: "O que nós encontramos são lesões na pele, na região das mamas, abaixo das mamas, que são bem compatíveis e características de que ela tenha usado faixas ou outras roupas apertadas com o objetivo de disfarçar a presença das mamas". $\mathrm{O}$ cotejamento ao uso do binder $F T M^{4}$ aparece atrelado à desconfiança manifestada pela vizinha e pelo médico. Essa informação não é utilizada a fim de entender as formas como homens transexuais lidam com a materialidade de seus corpos. Esse dispositivo corporal, representado na simulação, estratégia de subjetivação do corpo, é encarado não como constituinte das corporalidades, mas como elemento de dor, mal-estar e tortura que o corpo atribui a si para sustentar a sua mentira.

As desconfianças que partem da individualidade corpórea para o falseamento das relações sociais são mobilizadas através dos depoimentos de amigos, acionados junto à fala da repórter que afirma que Lourival "não gostava de médicos" e, ainda que estivesse com problemas de saúde, não se deixava internar, tampouco usava shorts ou camisetas, "só tomava banho de portas fechadas". Segundo a delegada, Lourival tomava muito cuidado para não ser visto nu e "dormia de calça e com o cinto muito apertado". Não procurar ajuda médica e resguardar o corpo são ações que supostamente correspondem a alguém que esconde algo. $\mathrm{O}$ verbo "gostar" individualiza a ação de Lourival como se ele pudesse escolher entre procurar ou não um serviço de atendimento em saúde. A condição social generalizada de precariedade e interdição ao sistema de saúde em atender as demandas das populações transexuais é apagada das circunstâncias sociais, na proposta de que ele teria alguma coisa a esconder.

As informações desse trecho também são apresentadas pela estratégia de subjetivação da simulação. Na tela, observam-se cenas em que alguém interpreta Lourival caminhando pela casa, sempre sozinho, espiando à janela a rua, entrando de maneira esgueirada e sorrateira no banheiro, despindo-se e retirando as faixas do peito. A imagem embaçada, escura e pouco nítida reforça a dramaticidade da narrativa de suspense. Assim, o texto jornalístico não apresenta nenhuma forma de compreensão empática para com Lourival.

A repórter diz: "Após a revelação, os vizinhos ficaram divididos". A essa afirmação, seguem as falas de três vizinhos: "Não imaginava, porque sempre teve os filhos aí que chama de pai, de pai, de pai... Cê nem imagina que é uma mulher"; "Dúvidas a gente tinha, né. Mas a gente nunca entrou... nunca perguntou nem nada, mas dúvida a gente tinha"; "Ele tinha um jeito assim... de homem-mulher. Pelo jeito de ele conversar com a gente, ele era muito delicado". A divisão a que a repórter se refere é entre os que diziam suspeitar ou não do "segredo". O comentário da última vizinha demarca um atributo considerado por ela feminino e, portanto, não coerente com um homem: a delicadeza. A reportagem permanece apostando na binaridade de gênero e não abre espaço para o questionamento sobre as condições de vida a que sujeitos e coletividades transexuais estão submetidos, condições biopolíticas responsáveis pelos cenários de precariedade e alto índice de violência.

A repórter conta: "Lourival dizia que era de Palmeira dos Índios, município de Alagoas, mas dias antes de morrer ele afirmou à cuidadora que sua verdadeira identidade seria Enedina Maria de Jesus e que teria nascido em Bom Conselho, interior de Pernambuco, e não em Alagoas". A delegada comenta: "A nossa esperança é que se localize algum parente... de Lourival e que nos possa dar um novo rumo a essa investigação". Sinalizamos a preposição "de", porque a delegada faz uma pausa e frisa o termo - mais uma vez, titubeia antes de se referir a Lourival, o que demonstra certa confusão e resistência a chamá-lo pelo masculino.

A reportagem conta que a produção do programa consultou os cartórios e igrejas das duas cidades, mas que não há registros de nascimento ou batismo com o nome de Enedina. A repórter questiona: "Mas, afinal, quem foi, de fato, Lourival

${ }^{4}$ Binder ou faixa female to male é um dispositivo socioestético para redução do volume dos seios utilizado por homens trans e por algumas pessoas não-binárias. Estético, pois implica em reduzir ou suprimir a aparência dos seios, e social, pois corresponde a um processo de elaboração da consciência e experiência corporal. 
Bezerra de Sá?" Como Lourival não tinha documentos de identificação com informações sobre filiação, só possuía um CPF em seu nome, a reportagem informa que "a expectativa é buscar a identificação a partir das digitais". A repórter entrevistou o diretor do Instituto de Identificação do Mato Grosso do Sul, que informou que as impressões digitais de Lourival não estavam cadastradas nos estados que até aquele momento haviam respondido à solicitação.

O texto jornalístico segue: "E como Lourival registrou crianças? Quem são os pais verdadeiros dos filhos registrados por ele?”. Novamente, insere-se o depoimento da filha:

Enquanto filha é muito difícil, uma história muito complicada, porque até então cresci achando que meu pai se chamava Lourival. Tá lá como pai. Aí quando faleceu era uma mulher. Ou seja, então, eu não tenho pai, eu não tenho mãe. Estamos aguardando um resultado de um DNA, pra saber se um de nós somos filhos da Lourival Bezerra de Sá, como mulher, pode ser mãe, e também da Maria Olina.

O médico afirma que os exames do útero indicam "que essa pessoa não teve filhos". Um professor de Direito complementa:

É inevitável que eles vão buscar a justiça para regularizar essa situação. Ou de retirar o nome de Lourival para ficar pai não identificado. Ou que eles mantenham esse nome através de uma ordem judicial, até utilizando-se da questão social que hoje é muito aplicada no nosso meio jurídico.

Essa é a única menção ao fato de que Lourival manteve durante 50 anos uma identificação social como homem. Porém, em nenhum momento, questiona-se se o mesmo aspecto pode ser considerado para permitir o enterro. A delegada diz:

O que é importante nessa investigação é que, quem tenha conhecimento de quem possa ser essa mulher que se identificou como Lourival e o motivo pelo qual ela fez isso, nos procure para auxiliar nesse esclarecimento, porque senão ela vai acabar sendo enterrada como indigente.

A reportagem finaliza com a fala da filha e de uma vizinha. É o único momento em que se demonstra uma abertura à alteridade. A filha diz: "Ela também deve ter uma história, tem um nome. É uma pessoa. Se cometeu algum erro ou não, não podia ser enterrada como indigente. Eu não desejo isso pra ela”. E a vizinha: "Eu quero que acabe com um final bom pro seu Lourival. Quero que ele tenha um enterro digno e quero que essa história seja desvendada, seja ela qual for".

\section{A produção das normatividades}

${ }^{5}$ Convenções de gênero são compreendidas como

"o conjunto de valores e ideais relativos ao imaginário sexual disponíveis na cultura e compartilhados, a partir dos quais os seres sociais pautam as suas ações e concepções de mundo, reproduzem e recriam estas mesmas convenções e as suas práticas" (BONETTI, 2011, on-line)

Ancorado em uma racionalidade balizada pelos princípios da objetividade, da imparcialidade e da universalidade, o jornalismo produz saberes que, de forma recorrente, pouco problematizam os valores hegemônicos inscritos nas narrativas. Tais valores são naturalizados e exaltados de tal forma que os fenômenos são explicados a partir de perspectivas de saber essencializadoras (VEIGA DA SILVA, 2015). Como afirmam Fabiana Moraes e Marcia Veiga da Silva (2019, p. 5), essa é uma "racionalidade que simplifica muito mais do que complexifica as formas como a realidade é concebida".

Não se pode negar que a crescente expressividade de identidades dissidentes às normas cisgênero e heterossexual na esfera pública, sobretudo midiática, traz desafios aos modos de narrar do jornalismo. Quando os acontecimentos narrados implicam sujeitos dissidentes, vemos comumente o reforço de convenções de gênero ${ }^{5}$ já cristalizadas nas discursividades sociais. Ao mesmo tempo, o cenário de uma sociedade midiatizada, com a proliferação das conversações em redes digitais, impulsiona um sistema de interação entre o jornalismo e os demais campos sociais. Isso possi- 
bilita respostas diversas e mobilizações que confrontam as narrativas jornalísticas sobre temas relacionados ao gênero e às sexualidades dissidentes, seja reivindicando coberturas mais afeitas à alteridade ou mesmo reiterando discursos de ódio contra esses sujeitos (BORELLI; MACHADO; DIAS, 2017, HENN; DIAS, 2019).

Ao produzir conhecimento, o jornalismo se constitui em relação aos sistemas de saber e de poder disciplinar nos quais se elaboram valores e hierarquias sociais dominantes (FOUCAULT, 2001). A orientação pela racionalidade dominante restringe as lentes de leitura do jornalismo, compromete a apuração, que já parte enviesada desde as suas perguntas orientadoras e, com isso, diminui as formas de compreensão da processualidade dos acontecimentos sociais. Nesse processo, as diferenças que não se enquadram na norma são transformadas em desigualdades (VEIGA DA SILVA, 2015) através de uma pluralidade de arranjos sociais resultantes da atuação entre os partícipes do cientificismo e do colonialismo (VEIGA DA SILVA; MORAES, 2020), bem como do binômio sexo-gênero, que estabelece modelos dicotômicos de compreensão das realidades corporais.

Como proposta interpretativa, ao invés de refletir o jornalismo como uma forma de conhecimento (GENRO FILHO, 1987; MEDITSCH, 1998), é possível, por perspectivas que se assumam como epistemologicamente orientadas, interrogar suas práticas mais lacunares, as insuficiências, hesitações e claudicações do processo jornalístico por sua inteligibilidade precária:

Longe de permitir o conhecimento da realidade social genericamente considerada ou de fenômenos sociais específicos, o jornalismo nos oferece quadros explicativos parciais, que mesmo levando em conta a regularidade de exposição às mais diversas mídias informativas, dificilmente permitiriam fazer do conjunto de dados singulares ofertados pelas narrativas jornalísticas eventos suficientes para ascender a compreensões mais sofisticadas nos níveis dos conhecimentos particulares e universais, outra vez recorrendo às categorias acionadas por Genro Filho (CARVALHO, 2019, p. 11).

O jornalismo constitui determinado tipo de conhecimento, não apenas em relação ao que narra do mundo, mas também em relação a suas próprias práticas. É preciso, no entanto, cotejar essa constituição de conhecimentos em relação a paradigmas, racionalidades e epistemologias dominantes (VEIGA DA SILVA, 2015). Nesse sentido, o conhecimento produzido pelo jornalismo deve ser lido pelo alcance limitado de suas linguagens, recursos e de sua própria razoabilidade.

No que se refere à reportagem, é possível argumentar sobre as condições de construção da narrativa: a utilização das estratégias de objetivação evidencia os procedimentos de pesquisa, apuração e edição de uma ampla variedade de fontes e recursos, mas que são mobilizados dentro de um padrão normativo de compreensão das realidades gênero-divergentes. Essa precariedade é constituinte do modo como o jornalismo produz suas formulações e de como agencia suas práticas tendo a cisgeneridade como horizonte absoluto das realidades sociocorporificadas, das técnicas corporais e dos regimes de verdade dos corpos (MAUSS, 2003; FOUCAULT, 2010).

A partir disso, a dramatização (estratégia de subjetivação), longe de ser uma representação dos dramas humanos de Lourival, é ela própria simulacro de um saber que precisa responder a si mesmo, enquadramento interpretativo que, mais do que oferecer uma experiência cognitivo-narrativa sobre o acontecimento, gera ontologias específicas sobre os sujeitos (BUTLER, 2017), estendidas, enquanto metanarrativa, a todo um grupo, coletividade ou população. Através da transformação das estratégias de objetivação em formas de subjetivar as realidades sociais, mantêm-se em funcionamento as separações entre a norma e o seu contrário e, por conseguinte, aquilo que ganha ou não o status de ser reconhecido como humano, processo de atribuição diferenciante do reconhecimento social e do usufruto da cidadania (BUTLER, 2017).

Com isso, os recursos narrativos são mobilizados a fim de suspeitar da idoneidade de seu caráter e suspender o luto pela perda de sua vida. Esse processo de 
desumanização se dá não só pela atuação dos agentes médicos, jurídicos e policiais, como também pelo jornalismo, responsável por sua última morte, terreno do simbólico que, ao reproduzir as normas sociais sem uma adequada reflexão, acaba por irromper mais uma vez na violação do corpo, no direito à intimidade, tomando para si o poder de decidir, sem a anuência do sujeito, suas próprias definições. Na descrição da reportagem, sinalizamos algumas dessas estratégias que conformam a inviabilidade do reconhecimento social. Elas apontam para uma racionalidade dominante que restringe consideravelmente as lentes de leitura do acontecimento e não permitem o reconhecimento de Lourival como uma pessoa transexual. Essa precariedade impossibilita o encontro com as alteridades e, ainda que o texto jornalístico seja permeado de perguntas (Figura 2), nenhuma delas interroga a própria racionalidade que orienta o relato.

Figura 2 - Perguntas

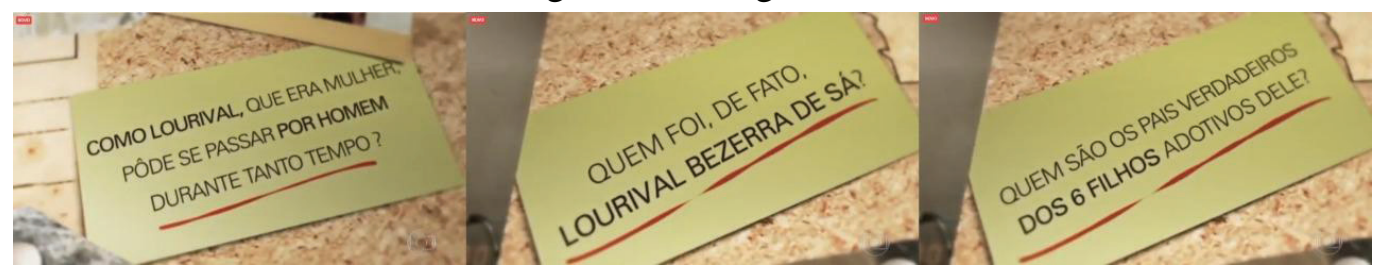

Créditos: Rede Globo, 2019 (captura de tela realizada pelos autores).

Na primeira pergunta, a narrativa parte da compreensão de que Lourival era uma mulher que se passou por homem durante muito tempo, informação que deriva principalmente do posicionamento das fontes. Ao dizer que Lourival era mulher, é ignorada a possibilidade de pensar a transgeneridade como existência legítima dos corpos, recorrendo para isso ao artifício narrativo que a todo momento o coloca sob suspeita.

Estabelecida a "verdade" sobre esse corpo mentir sobre si mesmo, a segunda pergunta questiona quem era "de fato" Lourival. A utilização dessa expressão reforça como verdadeira a "mentira" mantida por ele como única resposta possível. Com isso, a questão é deslocada para uma ontologia do sujeito traiçoeiro que produz um efeito de verdade não sobre as circunstâncias do ocorrido, mas sobre a condição do não reconhecimento da transgeneridade que edifica a reportagem. A terceira pergunta atinge um nível social mais amplo ao indagar como Lourival pôde adotar filhos. Para a adoção, parte-se da ideia de que ele enganou um sistema maior de atores e instituições, que enganou o Estado, burlou leis, deixando "pais verdadeiros" sem acesso a seus filhos.

Toda a sua existência acaba sendo eclipsada e a sua memória passa a ter como única referência o "mistério" que o fez viver socialmente como homem. No início da reportagem, há o depoimento dos vizinhos que o consideravam uma pessoa caridosa e querida por todos, mas essas informações são desqualificadas frente aos procedimentos que ele mantinha para esconder sua identidade. Com um olhar exotificante, a reportagem não complexifica o ocorrido, auxiliando no processo de desumanização de Lourival, criminalizando sua história de vida e sustentando a ideia de que ele falsificou sua identidade.

A todo momento, essas operações demarcam um campo semântico escorregadio, sob o pêndulo verdade/mentira, mistério/solução, tautologia jornalística que não se resolve ao final da reportagem. Não há resolução do mistério e sim sua sequência, a publicização como punição última de um crime que não lhe cabe. Precariedade narrativa, embora bem apurada, que sustenta a suspeita em vez da explicação, que prefere o disfarce ao reconhecimento, a dissimulação dramática à observação razoável dos referentes objetivos. 
A utilização das perguntas perfaz, além da intenção de manter o interesse pela história, um artifício retórico de ancoragem narrativa no trabalho de apuração jornalística. As perguntas são apresentadas como resultado de um processo de investigação. São articuladas como tal porque se pretendem respondidas ao final da reportagem e porque, além disso, são sentenças qualificadas como fio condutor da narrativa. Quem as responde detém, mais do que o poder de pôr fim ao mistério, o de sentenciar uma vida, pois elas carregam explicitamente formulações sobre as quais Lourival é interpretado. Na retórica do transgressor, o caráter da dúvida (FLUSSER, 2011) - necessário à formulação de saberes sociais -, se não desaparece, converge em acusação. Se há um disfarce em questão, parece estar relacionado não a Lourival, mas à fragilidade de sustentação da narrativa, à violação sistemática de sua história e memória e à conversão desses enunciados em horizonte que se empresta à violência, transfobia e normatização dos corpos das populações transexuais.

\section{Cisgeneridade como metanarrativa}

Em março de 2017, o Fantástico apresentou uma série com quatro reportagens intitulada Quem sou eu? ${ }^{6}$. Os episódios discutem a transgeneridade na infância, na adolescência, as violências e os arranjos familiares. As reportagens recorreram à linguagem audiovisual de teor lúdico e pedagógico. Além disso, no início da série, a repórter convida os telespectadores a se olharem no espelho: "imagine que o quê você vê não é o que você é” - estratégia que funciona como uma convocação às pessoas a se imaginarem como pessoas transexuais, um movimento do jornalismo afeito à alteridade e aberto às diferenças. A série foi reconhecida por abordar a transgeneridade de um modo diferente do que convencionalmente se vê nas mídias tradicionais. Mas como um programa que produziu uma série desse tipo também apresenta uma reportagem como a de Lourival?

Não há uma resposta simples para a questão, mas é possível afirmar que ambas convivem porque a transgeneridade ainda é um tema em disputa por diferentes atores e instituições sociais que carregam valores e moralidades variados em relação às questões de gênero. Gonçalves (2020) coloca em perspectiva diferentes conteúdos veiculados pelo Fantástico a respeito de pessoas transexuais, não-binárias e travestis entre 2017 e 2020, evidenciando que, para além de uma agenda pública que vem sendo conquistada, as práticas jornalísticas implicam racionalidades e princípios profissionais que se perfazem nas dinâmicas sociais e nos desdobramentos políticos desses enunciados. Esses conteúdos são dotados de poder hermenêutico, que suscitam interpretações sobre aquilo que narram, fazendo agir sobre eles uma série de outras ordens de fenômenos.

É notório na cultura brasileira um subtexto geral que inferioriza, incrimina, violenta e descarta os corpos de pessoas transexuais dentro de uma economia simbólica baseada na patologização das transidentidades, na criminalização de suas performances e na moralidade normativa de assumir os corpos "naturais" dentro de um regime de equivalência entre a constituição biológica e o gênero. A sujeição à cisgeneridade como paradigma da hierarquização dos corpos e a subalternidade social e simbólica atua como um sistema de controle mais amplo que perfaz os contextos e discursos sociais.

$\mathrm{O}$ acontecimento jornalístico emerge na vida social não quando Lourival morre, mas quando seu corpo é desnudado. Em sua dimensão simbólica, o acontecimento ganha vida quando diferentes vozes criam narrativas sobre o fato: os legistas que notificam o que chamaram de "divergência de gênero", a família que acolhe a "surpresa", a polícia que passa a investigar o caso, os vizinhos e conterrâneos que a cada roda de conversa comentam o ocorrido. Ou seja, o acontecimento penetra na vida da coletividade (FRANÇA, 2012), interrompendo as espacialidades cotidianas e passando a configurar redes de relações mais amplas.

${ }^{6}$ Disponível em: <https:// bit.ly/3ste3AD $>$. Acesso: 20 jul. 2019. 
Ao noticiar, o jornalismo passa também a construir esse acontecimento. A dimensão simbólica ganha outros contornos, já próprios da construção narrativa jornalística, a partir de critérios normativos, saberes instituídos, determinantes hegemônicos, dando projeção a uma ocorrência antes restrita a um âmbito mais localizado.

O corpo de Lourival torna-se um problema - para a medicina, para a polícia, para o direito e para o jornalismo -, o que demarca a sua própria materialidade na impossibilidade de ser assimilado pelas normas sociais que regem essas diferentes instâncias (BENTO, 2017). A dimensão metanarrativa da cisgeneridade pode ser entendida nas estruturas de apelo ético que são "plasmadas pelo narrador no momento em que o narrador se põe a narrar" (MOTTA, 2013, p. 138). Tema cujo interesse narrativo está profundamente arraigado aos imperativos de fundo moral e normativo de nossa sociedade.

Como metanarrativa, a cisgeneridade sustenta as estruturas sociais e os dispositivos que reclamam uma realidade única dos corpos, uma narrativa corporal aceita como autêntica e invariável. Esse sistema retira do corpo, inconformado às normas da cisgeneridade, o direito ao luto e à possibilidade de pleiteá-lo como uma vida possível de ser vivida, narrada em seus próprios termos e portadora de reconhecimento (BUTLER, 2017). Por meio de distintas estratégias, esse corpo passa a ser configurado como criminoso, cujo único fim previsto é o território da abjeção e da miserabilidade simbólica dos corpos-indigentes (KRISTEVA, 2004).

A apuração junto às fontes oficiais, aquelas que possuem "um lugar de fala já legitimado e que possa realizar, sem grandes investimentos o papel de escudo do jornalista" (GONÇALVES, 2014, p. 94), permitiu à reportagem construir uma iconografia do impostor - espaço quase lúdico e perverso da imaginação dramática. Essa dinâmica se caracteriza pela confiança irresponsável depositada nos peritos consultados que, no entanto, podem incidir de forma a testemunhar pela própria falibilidade da narrativa.

Como lembra Vera França (2012, p. 16), a vida narrativa do acontecimento é tão transformadora, e por vezes causa tamanho impacto, "que ela atua igualmente (e novamente) como acontecimento existencial - este, por sua vez, será comentado, e se transformará, de novo, numa segunda vida, numa espiral crescente". A narrativa, assim, não cessa. Permanece desdobrando sentidos: nas redes digitais, instantaneamente à veiculação, um amplo coletivo de atores passa a criticar a abordagem e a reivindicar uma abordagem mais aberta às alteridades. Da mesma forma, a racionalidade dominante do jornalismo passa a ser questionada recebendo leituras críticas e opositivas?.

\section{Considerações finais}

Além do problema da falibilidade das fontes, que autoriza a perpetuação da falta de senso crítico em relação ao tema, a reportagem sobre a morte de Lourival exclui as vozes de pessoas transexuais (indivíduos ou coletividades) que poderiam ser acionadas tanto como fontes preferenciais quanto como consultoras temáticas para que a reportagem não recaísse em uma representação desumana. Mais grave

${ }^{7}$ Foi o caso, por exemplo, das notas de repúdio à Rede Globo emitidas pela Rede Nacional de Pessoas Trans do Brasil (REDE-

TRANS) e pela Associação

Nacional de Travestis e

Transexuais (ANTRA)

Disponíveis em: $<$ https://

bit.ly/3nROzsZ> e <https://

bit.ly/2XLCFqi>. Acesso em: 10 jan. 2020. ainda é o problema da orientação racionalizada que se cristaliza na pouca reflexividade da apuração, que se preocupa mais em manifestar seu trabalho enunciativo, teatralizando sua ação em uma sequência dramática. As perguntas que servem como guias à narrativa, ao invés de serem assertivas aos problemas enfrentados pelas pessoas e populações transexuais, carregam um alto teor moralizante e taxativo. Com isso, a precariedade das práticas jornalísticas leva adiante um processo de narrativização normativa dos corpos transgêneros que tem por base a cisgeneridade como uma metanarrativa não apenas do jornalismo, mas de toda a sociedade.

Esse processo retira a humanidade possível das pessoas gênero-divergentes, atualizando uma retórica da culpa, do medo e da vergonha, que dificulta o desenvolvimento de horizontes sociais mais inclusivos. A reportagem, não reconhecen- 
do o gênero de Lourival, mais do que desqualificar sua memória, é responsável por sua última morte, uma dimensão simbólica do morrer em que seus direitos são retirados e sua existência passa a ser capturada, representada e ofertada à interpretação pública por sobre o avesso de sua trajetória.

Ao insistir na designação do gênero feminino, a narrativa reafirma uma série de constrangimentos que não dizem respeito apenas a Lourival, como um indivíduo, mas impacta a produção da inteligibilidade dos corpos trans e a manutenção dos regramentos sociais. Sem duvidar da cisgeneridade, as perguntas que faz o jornalismo não se revelam meramente como vazias, porque carregadas de moralidade e acusação. São mecanismos narrativos deliberados de produção desigual do acesso à cidadania e retenção simbólica do reconhecimento público ao domínio de alguns corpos privilegiados sobre outros. A apuração, assim como todas as etapas do processo de produção jornalística, é dependente da lente de leitura acionada. Enquanto for orientada pela categorização obliterada das identidades gênero-divergentes, casos que envolvam existências transexuais continuarão sendo vistos de modo enviesado e de maneira excludente - criminalizando, patologizando ou retirando a autonomia desses sujeitos.

Contudo, é importante perceber que a aparição na cena pública desses casos tende a suscitar um debate público que pode chegar a disputar ou desestabilizar os referentes enunciativos consolidados, inclusive as práticas jornalísticas. Reportagens como "Quem sou eu?", especialmente nas mídias tradicionais, valendo-se da subjetividade, da sensibilidade e da crítica às normas sociais instituídas, são consideradas inovadoras e mesmo emergentes, destoando das abordagens orientadas pelas racionalidades dominantes e excludentes da diferença (MORAES; VEIGA DA SILVA, 2019).

Quando essas narrativas são veiculadas, além de alargarem as possibilidades de compreensão das realidades sociais, complexificando as explicações e visões de mundo, acabam por convergir em capital simbólico pela qualidade da informação. Quando o jornalismo recorre a narrativas como a analisada, além do desserviço público, ocupa os atores sociais que precisam conclamar ações reparadoras mobilizando estratégias de resposta à mídia, convocando-a a cumprir as suas próprias competências presumidas. A narrativa sobre a morte de Lourival demonstra os limites de um jornalismo que ainda se orienta por uma matriz racional constituída pela cisgeneridade como paradigma de construção dos corpos, prática geradora de discurso transfóbico, engajado na produção e manutenção da desigualdade.

\section{Referências}

BENTO, B. Transviad@s: gênero, sexualidade e direitos humanos. Salvador: EDUFBA, 2017.

BONETTI, A. L. Gênero, poder e feminismos: as arapiracas pernambucanas e os sentidos de gênero da política feminista. Labrys, v. 20, on-line, 2011. Disponível em: <https://bit.ly/2I3uRJC>. Acesso em: 15 jan. 2020.

BORELLI, V.; MACHADO, A.; DIAS, M. S. M. Narrativas jornalísticas e possibilidades de resistência acerca do acontecimento \#SomosTodasVerônica: mídia, transfobia e violência. Conexão, v. 16, p. 113-133, 2017.

BUTLER, J. Quadros de guerra: quando a vida é passível de luto? Rio de Janeiro: Civilização Brasileira, 2017.

BUTLER, J. A vida psíquica do poder: teorias da sujeição. Belo Horizonte: Autêntica, 2018. 
CARVALHO, C. A. Uma necessária reavaliação conceitual e metodológica nos convoca: comunicação, jornalismo e relações de gênero. In: ENCONTRO ANUAL DA COMPÓS, 28, 2019, Porto Alegre. Anais... Porto Alegre: PUCRS, p. 1-20, 2019.

FLUSSER, V. A dúvida. São Paulo: Annablume, 2011.

FOUCAULT, M. Microfísica do poder. Rio de Janeiro: Graal, 2001.

FOUCAULT, M. História da sexualidade 1. A vontade de saber. São Paulo: Graal, 2010.

FRANÇA, V. O acontecimento e a mídia. Galaxia, n. 24, p. 10-21, dez. 2012.

GENRO FILHO, A. O segredo da pirâmide: para uma teoria marxista do jornalismo. Porto Alegre: Tchê!, 1987.

GONÇALVES, J. F. Quem fala no jornalismo? In: LEAL, B. S.; ANTUNES, E.; VAZ, P. B. (Org.). Para entender o jornalismo. Belo Horizonte: Autêntica, 2014, p. 89-101.

GONÇALVES, G. A fantástica reportagem sobre Suzy: Jornalismo, subjetividade, sujeição e afeto seletivo. In: ENCONTRO NACIONAL DE PESQUISADORES EM JORNALISMO, 18., 2020. Anais... Brasília: SBPJor, 2020.

GROSFOGUEL, R. Descolonizar as esquerdas ocidentalizadas: para além das esquerdas eurocêntricas rumo a uma esquerda transmoderna descolonial. Contemporânea, v. 2, n. 2, p. 337-362, 2012.

HALL, S. Cultura e representação. Rio de Janeiro: Ed. PUC-Rio; Apicuri, 2016.

HENN, R. C.; DIAS, M. S. M. “Se ela é não-binária, por que se referem no feminino?”: um corpo estranho em disputa. Famecos, v. 26, n. 3, p. 1-28, 2019.

HUERTA, L. L. Periodismo sin discriminación: reto del siglo XXI. El Cotidiano, n. 158, p. 87-91, nov.-dic. 2009.

JESUS, J. G. Transfobia e crimes de ódio: Assassinatos de pessoas transgênero como genocídio. História Agora, v.16, n. 2, p.101-123, 2013.

KRISTEVA, J. Poderes de la perversión. México: Siglo XXI, 2004.

LANZ, L. O corpo da roupa: a pessoa transgêneras entre a transgressão e a conformidade com as normas de gênero. Uma introdução aos estudos transgêneros. Curitiba: Transgente, 2017.

MAUSS, M. Sociologia e Antropologia. São Paulo: Cosac Naify, 2003.

MEDITSCH, E. Jornalismo como forma de conhecimento. Revista Brasileira da Comunicação, v. 21, n. 1, p. 25-38, jan.-jun. 1998.

MORAES, F.; VEIGA DA SILVA, M. A objetividade jornalística tem raça e tem gênero: a subjetividade como estratégia descolonizadora. In: ENCONTRO ANUAL DA COMPÓS, 28., Porto Alegre. Anais... Porto Alegre: PUCRS, 2019, p. 1-21, 2019. 
MOTTA, L. G. Análise pragmática da narrativa jornalística. In: LAGO, C. BENETTI, M. (Org.). Metodologia de pesquisa em jornalismo. Petrópolis: Vozes, 2008, p. 143-166.

MOTTA, L. G. Análise crítica da narrativa. Brasília: Ed. UnB, 2013.

RESENDE, F. A narratividade do discurso jornalístico - A questão do outro. Rumores, n. 6, p. 1-12, 2009.

RESENDE, F. Às desordens e aos sentidos: a narrativa como problema de pesquisa. In: SILVA, G. et al. (Org.). Jornalismo_contemporâneo: figurações, impasses e perspectivas. Salvador; Brasília: EDUFBA; COMPÓS, p. 119-138, 2011.

VEIGA DA SILVA, M. Saberes para a profissão, sujeitos possíveis: um olhar sobre a formação universitária dos jornalistas e as implicações dos regimes de poder-saber nas possibilidades de encontro com a alteridade. 2015. 276 p. Tese (Doutorado em Comunicação) - Universidade Federal do Rio Grande do Sul, Porto Alegre, 2015.

VEIGA DA SILVA, M.; MORAES, F. Onde está Ruanda no mapa? Decolonialidade, subjetividade e o racismo epistêmico do jornalismo. In: ENCONTRO ANUAL DA COMPÓS, 29., 2020, Campo Grande. Anais... Campo Grande: UFMS, 2020. 